was not going to carry biology very far forward. The boom was threatened by a bust.

No longer. As last week's fourth annual HUPO meeting in Munich demonstrated, the proteomics community is finally putting its house in order. And HUPO itself is playing an indispensable role. Formally established with a permanent secretariat in Montreal and supported in part by the Canadian government, it has set up committees whose members - the scientific heavyweights of proteomics - select initiatives to come under HUPO's wing. Such projects will now be required to maintain HUPO's standards, and will be supported by HUPO's training and education programmes.

Seven initiatives have already been chosen, including proteome projects in the brain, liver and plasma. Crucially, a major focus will be HUPO's Proteomics Standards Initiative, which is developing standards for data generation and presentation, including standardized formats for databases of the full range of proteomics measurements.

For example, protein-protein interaction data have been generated using both the 'yeast two-hybrid' system and mass spectroscopy, and held in different databases. The initiative has agreed on a common database format that sends users to information in both databases when asked which other proteins a specified protein

For mass spectroscopy data, the initiative is developing a list of information that a researcher must provide to accompany a claim that a protein has been identified, including the names of fragments and their individual masses. HUPO may eventually decide that the spectra themselves must be provided. interacts with.

Two related activities represent important new resources. One is a proteomics database called PRIDE (www.ebi.ac.uk/pride), developed jointly by the European Bioinformatics Institute at Hinxton near Cambridge, UK, and Ghent University in Belgium, which will use the HUPO standardized formats.

The second reflects HUPO's commitment to a broader definition of proteomics in the context of systems biology - using proteomic techniques to follow particular proteins in a biological pathway. Five major protein-interaction databases have agreed to share curating efforts and provide information in a HUPO standardized format, in a consortium called the International Molecular Exchange (IMEX).

Without the umbrella of HUPO, hopes for standardization in proteomics would have
"Without the umbrella of HUPO, researchers would have been more inclined to use their rivals' toothbrushes than their protocols." been bleak, with researchers being more inclined to use their rivals' toothbrushes than their protocols. HUPO is involving the entire international community in its discussions to ensure consensus, and has already brokered a surprising number of agreements, with journals ready to assist in enforcing standards.

Even as HUPO brings order to chaos, researchers are proving the value that proteomics is bringing to biology, not just in identifying biomarkers useful in medicine, but also in understanding how relatively simple genomic information is transformed into the wonder that is the functioning cell. At the end of the day, proteins, not genes, are the business end of biology.

\section{Endangered act}

\section{Efforts to reform the Endangered Species Act could harm America's most important conservation law.}

or three decades, one piece of legislation has been responsible more than any other for protecting land that serves as a habitat for threatened species of plants and animals in the United States. The 1973 Endangered Species Act sought to help ensure the survival of diminishing species by preserving their habitat and aiding the development of science-based 'recovery plans' for their survival. Since its enactment, the act has created and maintained unprecedented natural laboratories for ecologists, and has become a widely admired model for conservation laws worldwide.

As Congress convenes this week, an effort will be made, under the guise of 'reform', to weaken the act. In the final two years of George Bush's presidency, with Republican majorities in the House and Senate, parties that have sought for years to weaken the act - including the mining, oil and logging industries, and property developers see this as their best chance.

Drafts have been circulating of a proposed revision to the act that would give political appointees in the Department of the Interior far more discretion than they currently enjoy over how the act is exercised. Republican supporters of the bill seek to have it introduced by a Democrat so that the measure will appear bipartisan. But what is really needed is a show of bipartisan support for the existing law.

Scientific societies and universities need to become involved in this debate now, before the progress that has been made in conservation biology under the act is itself endangered.

The recent apparent rediscovery of the ivory-billed woodpecker in remnants of an old hardwood forest in Arkansas (see page 188) has amply demonstrated the value of the current law. As much as sixty years ago, ecologists were urging the protection of a forest in Louisiana, where what were thought to be the last of the statuesque woodpeckers were known to survive. But the calls were ignored, the forest was chopped, and the ivory-billed woodpeckers disappeared. Such an event would probably have been prevented by the Endangered Species Act. If the ivory-billed woodpecker has indeed re-emerged, it has done so in large part because
"If the ivory-billed woodpecker has indeed re-emerged, it has done so in large part because of the Endangered Species Act." the act protected the habitat of other threatened species.

Everyone loves a rare exotic bird, and the Bush administration has directed some $\$ 10$ million specifically towards the habitat and recovery of the ivory-billed woodpecker. But the best way of ensuring the survival of threatened species is through the solid legislative framework that the Endangered Species Act provides, not through single-species projects generated at the whim of politicians. The best outcome for ecology is that the current law be left alone. 